\title{
Journeys towards sociomathematical norms in the Foundation Phase
}

\begin{tabular}{|c|c|}
\hline \multicolumn{2}{|c|}{$\begin{array}{l}\text { Authors: } \\
\text { Samantha Morrison }{ }^{1} \text { (D) } \\
\text { Hamsa Venkat }^{1,2} \\
\text { Mike Askew }^{1} \text { (D) }\end{array}$} \\
\hline \multicolumn{2}{|c|}{$\begin{array}{l}\text { Affiliations: } \\
{ }^{1} \text { Wits School of Education, } \\
\text { Faculty of Humanities, } \\
\text { University of the } \\
\text { Witwatersrand, } \\
\text { Johannesburg, South Africa }\end{array}$} \\
\hline \multicolumn{2}{|c|}{$\begin{array}{l}{ }^{2} \text { School of Education and } \\
\text { Communication, Jönköping } \\
\text { University, Jönköping, } \\
\text { Sweden }\end{array}$} \\
\hline \multicolumn{2}{|c|}{$\begin{array}{l}\text { Corresponding author: } \\
\text { Samantha Morrison, } \\
\text { samantha.morrison@wits. } \\
\text { ac.za }\end{array}$} \\
\hline \multicolumn{2}{|c|}{$\begin{array}{l}\text { Dates: } \\
\text { Received: } 18 \text { Aug. } 2020 \\
\text { Accepted: } 04 \text { May } 2021 \\
\text { Published: } 04 \text { June } 2021\end{array}$} \\
\hline \multicolumn{2}{|c|}{$\begin{array}{l}\text { How to cite this article: } \\
\text { Morrison, S., Venkat, H. \& } \\
\text { Askew, M., 2021, 'Journeys } \\
\text { towards sociomathematical } \\
\text { norms in the Foundation } \\
\text { Phase', South African } \\
\text { Journal of Childhood } \\
\text { Education } 11(1), \text { a927. } \\
\text { https://doi.org/10.4102/ } \\
\text { sajce.v11i1.927 }\end{array}$} \\
\hline \multicolumn{2}{|c|}{$\begin{array}{l}\text { Copyright: } \\
\text { (C) 2021. The Authors. } \\
\text { Licensee: AOSIS. This work } \\
\text { is licensed under the } \\
\text { Creative Commons } \\
\text { Attribution License. }\end{array}$} \\
\hline \multicolumn{2}{|l|}{ Read online: } \\
\hline 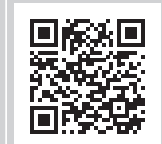 & $\begin{array}{l}\text { Scan this QR } \\
\text { code with your } \\
\text { smart phone or } \\
\text { mobile device } \\
\text { to read online. }\end{array}$ \\
\hline
\end{tabular}

Background: The co-establishment of social and sociomathematical norms in the microculture of South African classrooms and its possible effects on early number learning has largely been unexplored. Social norms are considered to be general classroom norms that are relevant in any teaching and learning space, whilst sociomathematical norms are specific to the mathematical aspects of students' working.

Aim: In the midst of poor numeracy outcomes in South African schools, our interest lies in the connections between the establishment of particular norms and the affordances or constraints for learning that they provided. Part of our interest, in a context where sense-making, cooperative working and mathematical progression beyond one-by-one counting have been described as infrequent in Foundation Phase mathematics learning, was to explore whether it was possible to institute norms related to these aspects.

Setting: We report on the social and sociomathematical norms established within group intervention sessions with two groups of four Grade 2 learners across 9 weeks of intervention in a suburban school which serves a historically disadvantaged learner population.

Methods: The frequency of specific norm codes was used to determine the normative behaviour within groups across intervention lessons.

Results: Two significant inferences are drawn from study results: a culture of co-operative working based on social norms was needed in the grouped learning space before sociomathematical norms could be foregrounded within the same space; and one particular sociomathematical norm - 'use the structure of $10^{\prime}$ - was particularly important as the 'hand hold' that allowed for progression in participants' early number skills.

Keywords: counting-based; learners'; sense-making; co-operative working; poor numeracy.

\section{Introduction}

This article describes the normative behaviour of two groups of South African Grade 2 learners during grouped intervention that focused on improving their early number skills. The intervention was based on an adapted version of Wright, Martland and Stafford's (2006) Mathematics Recovery (MR) programme. Children's acquisition of early number knowledge is highly personalised and influenced by the context in which mathematics evolves (Shumway 2011). In every classroom, interaction between the teacher and learners, and between learners themselves, forms part of this context which is referred to as the 'classroom culture' or the 'classroom ethos' (Askew 2016; Yackel \& Cobb 1996). Drawing on the work of Cobb, Yackel and colleagues (Yackel \& Cobb 1996; Yackel \& Rasmussen 2002), we refer to two distinct types of norms that were established within the microculture of each group, namely, social norms (SNs) or general classroom norms and sociomathematical norms (SMNs) that refer to norms specifically associated with classroom mathematical activity. Whilst the two intervention groups consisted of different participants with unique personalities and varying levels of mathematical ability, there were similar trends in how norms came to be established within each group. We use examples taken from our analysis of grouped intervention lessons to show that one particular SMN - 'use the structure of $10^{\prime}$ leveraged participants' progression along the MR literature-based trajectory for additive reasoning, that is, progression from counting-based strategies like 'count all' and 'count on' to calculation strategies premised on the base-10 number structure.

Whilst various aspects related to South Africa's 'maths crisis' - such as gaps in teacher content knowledge and poor curriculum coverage - have been reported in the literature (Spaull 2013),

Note: Special Collection: Supporting Excellence in Early Childhood Mathematics Education. 
less consideration has been given to the influence that sociological aspects of classroom culture have on learning outcomes. Thus, the potential of viewing mathematics teaching and learning as a social enterprise (Boaler 1998) has been leveraged in limited ways. Broader evidence on the ground suggests a South African Foundation Phase mathematics pedagogy that is centred around whole-class teaching, where teacher talk dominates lessons and where 'group work' consists of 4-10 learners seated around a table with one piece of paper and a pencil which one learner uses whilst the others watch (Ensor et al. 2009).

In the broader mathematics education field, links have been made between sociological and psychological perspectives of learning (Cobb \& Yackel 1996; Yackel \& Rasmussen 2002). Drawing on the work of Cobb and colleagues (McClain \& Cobb 2001; Cobb \& Yackel 1996), this article is based on the premise that the norms developed within the microculture of a mathematics classroom influence children's learning. The work of Cobb and colleagues (McClain \& Cobb 2001; Cobb \& Yackel 1996) resonates with international research related to other sociological aspects of learning, such as the link between cultural beliefs about the role of women and girls' maths, science and reading skills (Rodríguez-Planas \& Nollenberger 2018), and the development of SMNs through the use of visual learning aids (Widodo, Turmudi \& Dahlan 2019). In local literature, research that links the sociological and psychological aspects of learning mathematics includes a focus on the role of teacher pedagogy in shaping learners' mathematical identities and the promotion of equity and access to mathematics (Gardee 2019a, 2019b). Beyond mathematics education, local literature has also linked low learner performance with the absence of attention to values education and discipline in South African schools (Maphalala \& Mpofu 2018; Segalo \& Rambuda 2018; Solomon \& Fataar 2011). As with other research that draws links between sociological and psychological perspectives on learning, we argue that a greater focus on the norms established within a mathematics classroom can provide affordances for learners to make sense of the mathematics offered.

\section{Background}

The background of this story is the first author's doctoral thesis (Morrison 2018) that reported on how small-scale intervention based on MR scaled up the early number skills of 10 second graders, eight of whom received grouped intervention (two groups of four), in a South African public school. This suburban school was identified by the district as 'underperforming' in mathematics relative to their quintile five status (Spaull et al. 2016). As part of the MR programme, individual video-recorded task-based interviews using MR assessments were used to determine participants' most advanced additive strategies before and immediately following the intervention (Wright et al. 2006). These individual task-based interviews served as pre- and post-tests. Also, part of MR is the Learning
Framework in Number (LFIN) that sets out the trajectory for several aspects of number along which children usually progress in their learning of early number. Determining progression along the LFIN trajectory is based centrally on the sophistication of children's strategies for early arithmetical learning (SEAL), which forms the main part of the LFIN (Wright et al. 2006). Briefly, the different stages of the LFIN SEAL aspect are as follows: stage 0 - cannot count perceived items; stage 1 - counts perceived items using 'count all'; stage 2 - counts figurative items using 'count all'; stage 3 - uses curtailed counting strategies like 'count on'; stage 4 - uses the difference conception of subtraction (e.g. use 'count-down-to' to solve 18-16); and stage 5 - uses a range of non-count-by-one strategies premised on structuring number and known number facts. The LFIN descriptors for the different SEAL stages were used to code learners' responses to MR assessment tasks and determine their most advanced additive strategy (Wright et al. 2006). For the purposes of this article, we grouped SEAL stages into two broad categories, namely, 'calculation-by-counting' with pushes into reified use of number at the upper end and 'calculation-by-structuring' with pushes into purely mental calculations (Van den Heuvel-Panhuizen 2008). We grouped SEAL stages 1-3 under the broad category of 'calculation-by-counting' and SEAL stages 4 and 5 under 'calculation-by-structuring'. Table 1 presents our analysis of the eight group work participants' additive strategies across pre- and post-tests, using these broad categories.

Table 1 indicates two completely different pictures of the additive strategies used by participants who received grouped intervention just before and immediately after intervention. Before intervention, seven of the eight participants used 'calculation-by-counting' strategies to solve additive tasks: two of these learners used 'count all' (SEAL 2) and five learners used 'count on' (SEAL 3), with only one learner able to use subtraction as difference (SEAL 4) that is linked to 'calculation-by-structuring'. Immediately after intervention, seven learners used 'calculation-bystructuring' strategies using the base-10 structure to move beyond counting in ones, as well as purely mental strategies like known or derived facts. Of these seven learners, three were at SEAL stage 5 and four learners were at SEAL stage 4. Only one learner in the post-test used the 'count on' strategy that falls under 'calculation-by-counting'. Thus, whilst only one out of the eight participants used efficient 'calculation-by-structuring' strategies to solve additive tasks before intervention, seven of the eight participants used efficient calculation strategies after intervention. The fact that this kind of change could be effected in small groups was an encouraging result, given Wright et al.'s (2006) developed country model of individual working with the MR model, and given the two- to four-grade lag that has

TABLE 1: Participants' additive strategies in pre- and post-test.

\begin{tabular}{lcc}
\hline Number of learners & $\begin{array}{c}\text { Calculation-by-counting } \\
\text { (SEAL stages 1-3) }\end{array}$ & $\begin{array}{c}\text { Calculation-by-structuring } \\
\text { (SEAL stages 4-5) }\end{array}$ \\
\hline Number of learners in pre-test & 7 & 1 \\
Number of learners in post-test & 1 & 7 \\
\hline
\end{tabular}

SEAL, strategies for early arithmetical learning. 
been identified in $75 \%-80 \%$ of children in public schools in South Africa (Spaull 2013).

\section{Research aim and question}

Our aim in studying certain normative behaviour within each intervention group was to understand the connections between the establishment of norms and group members' opportunity to learn early number. Results from the first author's doctoral study showed that learners who received grouped intervention based on MR progressed in their early number learning (Morrison 2018). However, the normative behaviour within intervention groups was not a focus of that study - hence our interest in analysing the establishment of these norms and their influence on participants' early number learning. Taken together, our interest led to the following research question: in what ways did the establishment of norms during grouped intervention influence participants' learning of early number?

\section{Theoretical framing or definitions of key concepts}

Based on a social constructivist perspective, we view the relation between individual and collective learning as 'reflexive' (Yackel \& Cobb 1996). This means that as individual learners construct mathematical meaning through engagement in classroom activities, they simultaneously contribute to the shared culture or ethos of the classroom. In turn, the microculture of a mathematics classroom has the ability to shape certain aspects of individual and collective mathematical learning. A shared classroom culture that guides the nature of interactions can be created when the teacher coordinates the academic tasks given with a social participation structure (Erickson 1982). 'Revoicing' is one of the strategies that can be used to structure the social participation between members of a group (O'Connor \& Michaels 1996). By revoicing group members' offers, the teacher structures the discursive patterns within the group as members talk about elements of the academic task. This strategy was implemented in the study being reported on as learners were encouraged to not only share their solutions to tasks but also to share their underlying reasoning - with the use of 'revoicing' where needed. Linguistic structure, or a shared way of talking, is not the only way in which social participation within a group can be structured - setting up classroom norms can also structure participation within a group.

\section{Sociomathematical norms}

Cobb and Yackel's notion of SMNs - normative classroom aspects specific to learners' mathematical activity - include understandings of what counts as 'mathematically different' or 'mathematically sophisticated' as well as what counts as an 'acceptable mathematical explanation and justification' (Yackel \& Cobb 1996:461). According to these authors, SMNs are not predetermined criteria introduced into the small-group context from the outside, but are interactively set up by the learners and teachers as they develop a 'taken-as-shared' understanding of such norms. Research evidence suggests that in addition to regulating participation in small-group and class discussions, SMNs also provide learning opportunities that support learners' higher-order cognitive activities, like comparing solution strategies and judging the similarities and differences inherent therein (Yackel \& Cobb 1996). In related research conducted by Cobb (1995) a reflexive relationship between children's individual learning and their small-group interactions is reported.

Using Cobb's work as a springboard, certain SMNs were set as 'beacons' to guide the nature of group interactions during intervention sessions. The framing of each norm was guided by participants' understanding of the mathematics being taught and the norms already in place within the broader culture of the school. Thus, during intervention, these norms were framed slightly differently from those commonly mentioned in the literature as Yackel and Cobb (1996:406) have noted: 'what becomes mathematically normative in a classroom is constrained by the current goals, beliefs, suppositions and assumptions of the classroom participants'. Because SMNs are interactively set up in any classroom or group, the frequency with which norms were initiated and/or enacted within each intervention group differed. A description of the norms established within the intervention space for both groups follows next, together with a literaturebased rationale for each. These are listed in order from the norm with the lowest frequency during intervention to the one with the highest.

\section{Sociomathematical norms established in groups during intervention}

1. Do you know a different way?

Rather than having group members trying to memorise one 'right way' of solving tasks, learners were encouraged to think flexibly (Anghileri 2006; McIntosh, Reys \& Reys 1997). This norm was also used to keep participants engaged - that means learners could not anticipate that the instructor would move on to another task as soon as the correct answer was offered by someone in the group.

2. Do you know a quicker way?

'Procedural fluency' is one of the strands of mathematical proficiency (Kilpatrick, Swafford \& Findell 2001) which research shows is lacking in the South African terrain (Schollar 2008) - thus, this norm was put in place during intervention sessions. This norm ties in with the third norm (do not count in ones) but also goes further than that as some inefficient strategies (for certain calculations) do not involve counting-in-ones. For example, solving '201-198' using the column method is inefficient as it involves extensive and error-prone decomposition, with the difference conception of subtraction using 'count-upto' being more efficient.

\section{Do not count in ones}

When prompted, most learners were able to use the 'count-on' strategy to solve simple additive tasks at the outset of intervention - which is more sophisticated than the inefficient 'count all' strategy prevalent on the 
ground (Schollar 2008), but still involves counting in ones. Thus, a goal during intervention was to move learners from counting-in-ones to more efficient mental strategies premised on base-10 - for example, by working questions like $7+5$ as $7+3+2$ (bridgingthrough-10), or questions like $35+12$ as $35+10+2$ (jumping in 10s).

\section{Use the structure of 5}

Using the structure of five also underpins a range of mental calculation strategies available to children. For example, the child who sees eight as ' 5 and 3 more' will be able to draw on this knowledge when using a strategy such as 'bridging-through- 10 ' to solve $35+8$ as $35+5=40$ and $40+3=43$ (Ellemor-Collins \& Wright 2009).

5. Multiple representations can be used for showing or doing the same thing

Previous research has pointed to an over-reliance on concrete resources used to enact calculation-by-counting strategies within South African Foundation Phase classrooms (Ensor et al. 2009). This norm encouraged learners to think flexibly and to work within increasingly more abstract settings that engendered mental calculation strategies. Using multiple representations ties into flexible ways of thinking about mathematics (Anghileri 2006; McIntosh et al. 1997) and can link to the norm 'Do you know a different way?'.

6. Be ready to agree with or refute another's offer, giving reasons

This norm arises from the premise that mathematics is a social enterprise (NCTM 2000) and that children's acquisition of early number knowledge does not only come from their own working with number but from the group's varied experiences with number. The initial intention was to build this norm to a place where learners developed skills of mathematical argumentation (Yackel \& Cobb 1996), but because most learners struggled to simply express their thinking using 'math talk' (in a broader culture where highly authoritarian modes of classroom interaction have been noted as widely prevalent), this norm came to be diluted to the point where learners were often only asked if they agreed or disagreed with the offering of a peer. This norm was thus enacted as a disciplinary measure (to get learners to attend to what their peers were saying) and was thus more akin to a social norm.

\section{Distancing the setting}

One of the tenets of the MR programme is 'distancing the setting'. Tasks initially posed using concrete settings like counters or bundling sticks were later posed with the same settings that were flashed and screened (but still available if needed); and finally, settings were removed altogether. In this way, learners were encouraged to become less dependent on concrete materials and move to developing visualisation skills and the use of mental strategies (Wright, Ellemor-Collins \& Tabor 2012).
8. Explain or justify your solutions or offers to the group From the outset, learners were expected to not only give an answer to a task posed during intervention but also to explain their reasoning. This norm was instituted to illuminate the strategies available to the learner at that time so that other group members would gain insight into his or her mathematical reasoning and learn from it (if they did not know how to solve the task) or to compare it with their own reasoning (if they solved the task in another way).

\section{Use the structure of $\mathbf{1 0}$}

Literature in the field of early number learning shows that learners who use the structure of 10 (or 10 as a benchmark) have a better sense of the size of numbers, can reason in multiples of 10 and also make use of estimation to gauge whether a result makes sense or not (Ellemor-Collins \& Wright 2009). For example, a learner who is able to use the structure of 10 will easily be aware of his or her error if he or she gets ' 316 ' as an answer to calculating ' $29+17$ ' using the column method, because he or she will reason that 29 is close to 30 and 17 is close to 20 , so the answer should be close to 50 . Also, a learner who can reason in tens will be able to solve 48-23 as 40-20 $=20$, then $8-3=5$ and $20+5=25$ (a method that splits the tens and units) or as $48-20=28 \rightarrow 28-3=25$ (a method based on subtracting the tens in the subtrahend from the first number and then subtracting the units in the subtrahend from the result).

\section{Social norms}

Social norms differ from SMNs in that the former are not specifically linked to mathematical activity that takes place within a classroom setting. Social norms refer to normative behaviour that takes place in any classroom or learning space. When learners in an art class stand to greet another teacher entering their classroom, this is a social norm as the same behaviour would be expected from those learners if they were in a technology class. The SNs that were established in both groups during the intervention period were:

1. Do not laugh if another group member makes a mistake.

2. Work as a team, take turns, no competition.

3. Work quietly, do not disrupt other participants.

4. No 'popcorn' offers.

5. Be attentive to your peers' offers.

6. Pay attention and participate in the tasks posed.

Whilst the above SNs are largely self-explanatory, we point out the difference between norms that seem similar. Social norms 5 and 6 are very similar - but a useful distinction for us was that the latter was applicable when a learner was being inattentive to what the teacher was doing or saying, whilst the former referred to the same learner action, but this time in response to what a peer was saying or doing. Social norm 4, no 'popcorn' offers, related to learners' 'popping' their hands up as an indication that they wanted to answer even though the task was posed to another learner. From the 
onset of intervention, the intervention teacher said the name of the intended respondent before posing a task in order to ensure broad and directed participation across all learners in the group. Despite this, learners often bounced up and down on their seats with their hands raised or shouted out their offer in excitement. One teacher at the school remarked how learners were like popcorn jumping around in a pot (when they were eager to offer an answer) - thus this norm was framed as 'no popcorn offers'.

\section{Methods}

Eight middle-attaining Grade 2 learners (two groups of four) from a public school in the north of Johannesburg had two 40min intervention sessions based on MR per week for 9 weeks. Intervention, in the form of a teaching experiment (Steffe \& Thompson 2000), was topped and tailed by individual taskbased interviews from the MR programme which served as pre- and post-tests. Intervention sessions were video-recorded to capture patterns of interaction between group members (this included their gestures, talk, inscriptions and artefact use); these recordings were then transcribed. Methodologically, normative behaviour is inferred by identifying regularities in patterns of social interaction in the classroom (Yackel \& Cobb 1996:406). Patterns of interaction that were identified as social or SMNs for each group were those that appeared at least three times in more than one intervention session. Using full transcriptions of each intervention lesson that included details of gestures, talk, inscriptions and artefact use, we determined which patterns of interaction could be regarded as a 'regularity' within the group's intervention space, and we took these to be norms and outlined indicators for each. Thereafter we reread all the transcripts, re-watched video data where clarity was needed and noted every instance where a norm was initiated or enacted within the intervention space. The information noted was the following: the sequence number of the lesson, the group member initiating the norm (and the person to whom the exchange was directed), the task posed and the response given. After doing the above for both groups, the frequency of norms established within each intervention space was tallied and recorded in tables from the highest frequency to the lowest. We grouped the first half of intervention lessons (i.e. lessons 2-9) in one table and the second half (i.e. lessons 10-17) in another table as this allowed us to compare the frequency of norms between individual lessons and across the first and second half of the intervention sequence.

\section{Analysis of social and sociomathematical norms}

Using transcripts of each intervention session, we looked for regularities or patterns within the interaction between members of a group and developed codes related to literature as well as codes that emerged in a 'grounded' way. At the onset of intervention, participants often laughed at a peer who made an incorrect offer or who struggled with a task. Thus, the social norm 'do not laugh at a peer' was set up to address what was happening on the ground. When a learner answered a task, the follow-up question often posed was, 'How do you know' or 'Explain to us how you worked that out'. This is an example of interaction that was coded as a sociomathematical norm that relates closely to literature, namely 'explain or justify your solution or offer to the group'.

Altogether we identified nine SMNs and six SNs that were established within the microculture of both groups. As already noted, some of the SMNs related closely to one another, for example, 'do not count in ones', was closely linked to 'do you know a quicker way?' as learners who counted in ones often took a long time to complete the calculation. In some cases, one instance could be coded under multiple norms - but here the norm that was foregrounded guided the coding. For example, in the extract that follows, in line 3, Julie answers the teachers' question saying, 'There are twelve people on the bus: ten people on the bottom and two on top'. Julie's response could be coded as SMN \#9 'use the structure of ten' because Julie used the 10-structure in her reasoning. However, the artefact used here is a bus with two rows of 10 - the bottom row with 10 counters and the top row with two counters - that was flashed and screened. Thus, it was expected that learners would use the 10-structure inherent in the artefact to subitise the total number of people on the bus. For Julie - one of the stronger attainers who previously showed facility with using base-10 - the significance of her response is that she offered a justification for her answer without prompting, thus the code: SMN \#8.

\section{Examples of coding}

Next, we share a transcription extract from lesson 12 (group 1) to show how certain interactions were coded using a few of the SMNs previously outlined: \#8 (explain your offer), \#6 (agree with or refute a peer's offer), \#1 (do you know a different way?) and \#7 (distancing the setting) as well as SNs: \#5 (be attentive to your peers' offerings) and \#4 (no 'popcorn offers'):

L1 The Big Bus picture with red counters showing 12 people on the bus is flashed to the group.

L2 T: How many people are on the bus, Julie?

L3 Julie: There are twelve people on the bus: ten people on the bottom and two on top. (SMN \#8)

L4 T: (Screens the bus) Four people get off. (Teacher removes four counters while bus is screened: two from the top and two from the bottom row and places these alongside the screened bus).

L6

L7 Julie: Eight (immediately)

L8 T: Kgomo, is she right? (SMN \#6)

L9 Kgo: Yes

L10 T: How do you know, Kgomo? (SMN \#8)

L11 Kgo: Mmm... there were twelve?

L12 T: Yes

L13 Kgo: Then you took away ten ... I mean one, ... then two ... (remains silent)

L14 T: But there were four (touches four counters removed from bus)... four got off. 
Kgomo does not say anything more. Teacher reminds Kgomo of the need to follow what is said

L16 by peers in order to agree or disagree with them. (SN \#5)

L17 T: (To Kyle) There were twelve people on the bus and four got off (touches the counters). Julie says there are eight left on the bus. Is she right? (SMN \#6)

L19 Kyle: No

L20 T: Why not? (SMN \#8)

L21 Kyle: (Silent for a few seconds)

L22 T: How many are left?

L23 Kyle: There were twelve people, then you took away two at the top and two at the bottom row and

L24 then you had...

L25 Khosi pops her hand up.

L26 T: (Looks at Khosi) Put your hand down! (SN \#4)

L27 Kgo: Eight!

L28 Teacher's expression lets Kgomo know that she was not happy with his 'popcorn offer' (SN \#4)

L29 but allows him to explain his reasoning, which was a repetition of what Kyle just said.

L30 T: I want you guys to picture the number of people on the bus (SMN \#7), then first take away

L31 what's on top and then take away the rest from the bottom.

L32 Khosi: You can also know the answer using addition because eight plus four is twelve. (SMN \#1)

In the above extract, the teacher's action of screening the bus (in lines 4-6) is coded SMN \#7: distancing the setting. The next time the same code is used (line 30) when the teacher encouraged the group to use their visualisation skills when solving the task. These interactions get the same code because the message conveyed is the same, that is, do not rely on concrete materials, rather use your visualisation skills to help you solve the task mentally. Further, whilst presentation of the task (12-4) ran across three lines (lines 4-6) and the word 'screen/ed' was used three times, this is coded as one instance because the entire exchange refers to the same task.

Similarly, in lines 10 and 20, the teacher's words 'How do you know, Kgomo?' and 'Why not?' (directed at Kyle) have been coded SMN \#8 because they have the same purpose: explain your offer to the group. In both cases, the learner to whom the norm is directed did not answer the initial task, but when they agreed with (in Kgomo's case) or refuted (Kyle) their peer's offer, they were expected to have a reason for doing so.
SN \#4: no popcorn offer is coded twice in this extract (lines 26 and 28). In the first instance, the teacher told Khosi to put her hand down as the task was posed to another learner. In the second case, the teacher conveyed the same message to Kgomo by giving him a stern look after he shouted out the answer. Here, the teacher used different modes of communication but the message was the same.

The teacher initiated SMN \#6: agree with or refute another's offer in lines 8 and 18 when she asked Kgomo and Kyle whether they agreed with Julie's offer or not. SN \#5: be attentive to your peers' offerings was established in lines 15 and 16 when the teacher reprimanded Kgomo for not listening to what Julie had said.

We next present our analysis of the frequency of norms established in both groups over the course of intervention in tabular form and then discuss these further.

\section{Results and discussion}

Table 2 shows that 189 SNs were set up in group 1 for lessons 2-9 and 79 SNs in the same group for lessons 10-17. Across the same intervention period for group 2, 98 SNs were set up during lessons 2-9 and 58 during lessons 10-17. In both groups, more $\mathrm{SNs}$ were established in the intervention space during the first half of intervention than the second half. What we infer from this result is that more had to be done to establish a shared way of working between group members during the first half of intervention compared to the second half. Also, in group 1, 460 SMNs were established during lessons 2-9 and 415 SMNs across lessons 10-17. During the same period, group 2 established 553 SMNs for lessons 2-9 and 602 SMNs for lessons 10-17. Thus, more SMNs were established in both groups across the first and second half of intervention compared to SNs for the same period. Although the percentage of SMNs setup in each group was higher than that of the SNs, we also see that the difference in this proportion increased over time - that is, from $42 \%$ in the first half of intervention to $68 \%$ in the second half for group 1 and from $70 \%$ to $82 \%$ for the same period for group 2 . The greater difference in proportion indicates that a greater number of all the norms established in both groups over time were SMNs, pointing to an emphasis in the intervention on mathematical learning, but in ways that were supported by attention to the SNs of working in the small group environments.

The first author's reflective notes on implementation of lessons - that group 1 struggled more than group 2 to work

TABLE 2: Social norms and sociomathematical norms for groups 1 and 2 divided into first and second half of intervention.

\begin{tabular}{|c|c|c|c|c|c|c|c|c|}
\hline \multirow[t]{3}{*}{ Norms } & \multicolumn{4}{|c|}{ Group 1} & \multicolumn{4}{|c|}{ Group 2} \\
\hline & \multicolumn{2}{|c|}{ L 2-9 } & \multicolumn{2}{|c|}{ L 10-17 } & \multicolumn{2}{|c|}{ L 2-9 } & \multicolumn{2}{|c|}{ L 10-17 } \\
\hline & $N$ & $\%$ & $N$ & $\%$ & $N$ & $\%$ & $N$ & $\%$ \\
\hline Social norms (SNs) & 189 & 29 & 79 & 16 & 98 & 15 & 58 & 9 \\
\hline Sociomathematical norms (SMNs) & 460 & 71 & 415 & 84 & 553 & 85 & 602 & 91 \\
\hline Total & 649 & - & 494 & - & 651 & - & 660 & - \\
\hline Difference & - & 42 & - & 68 & - & 70 & - & 82 \\
\hline
\end{tabular}


TABLE 3: Total number of social norms and sociomathematical norms for groups 1 and 2.

\begin{tabular}{lcccccc}
\hline \multirow{2}{*}{ Norms } & Total & \multicolumn{2}{c}{ Group 1 } & & \multicolumn{2}{c}{ Group 2 } \\
\cline { 3 - 4 } \cline { 6 - 7 } & & $\boldsymbol{N}$ & $\mathbf{\%}$ & & $\boldsymbol{N}$ & $\mathbf{\%}$ \\
\hline Social norms (SNs) & 424 & 268 & 63 & & 156 & 37 \\
Sociomathematical norms (SMNs) & 2030 & 875 & 43 & & 1155 & 57 \\
\hline
\end{tabular}

TABLE 4: Total number of sociomathematical norms compared to sociomathematical norm \#9.

\begin{tabular}{lccccc}
\hline Norms & \multicolumn{3}{c}{ Group 1 } & & \multicolumn{2}{c}{ Group 2 } \\
\cline { 2 - 3 } \cline { 5 - 6 } & $\boldsymbol{N}$ & $\mathbf{\%}$ & & $\boldsymbol{N}$ & $\mathbf{\%}$ \\
\hline Total SMNs & $\mathbf{8 7 5}$ & - & & $\mathbf{1 1 5 5}$ & - \\
SMN \#9 & 491 & 56 & & 711 & 62 \\
SMNs \#1-\#8 & 384 & 44 & & 444 & 38 \\
Difference & - & 12 & & - & 24 \\
\hline
\end{tabular}

SMN, sociomathematical norms.

collaboratively during intervention - can be corroborated by the results shown in Table 3. That is, more SNs were set up in group 1 compared to group 2, that is, $63 \%$ compared to $37 \%$ of all SNs established by both groups over the course of intervention. Also, $43 \%$ of the total SMNs established in both groups across intervention came from group 1 and 57\% came from group 2. So, whilst group 1 had more SNs established within its microculture, this group also had less SMNs established during intervention than group 2. This result adds to the South African evidence of disruptive behaviour affecting the extent of openings to establish SMNs and mathematical learning as a consequence - a problem that has been highlighted in prior early grades' work (Roberts \& Venkat 2016).

Table 4 indicates the number of times sociomathematical norm \#9 'use the structure of 10 ' was initiated and enacted in each group across the intervention period compared to SMNs \#1 - \#8. From the table, it is clear that the number of times SMN \#9 was established in each group outweighed the total number of all other SMNs established in each group over the same period. The fact that SMN \#9: 'use the structure of ten' was initiated and enacted more times in both groups over the course of intervention than all other SMNs combined attests to the fact that using 'base-10 thinking' became the overarching goal during intervention. When comparing the number of times SMN \#9 was established in relation to the total number of SMNs established in each group across intervention, we see a difference of $12 \%$ for group 1 and $24 \%$ for group 2. So proportionally, a greater percentage of all SMNs initiated and enacted in group 2 were SMN \#9' use the structure of $10^{\prime}$, which is double the frequency with which the same norm was established in group 1 when compared to all other SMNs.

\section{Conclusion}

By looking at the pattern of norms established within the microculture of each group over the intervention period, we have been able to corroborate earlier evidence from local studies - that learning mathematics is often not experienced as a social endeavour on the ground (Ensor et al. 2009).

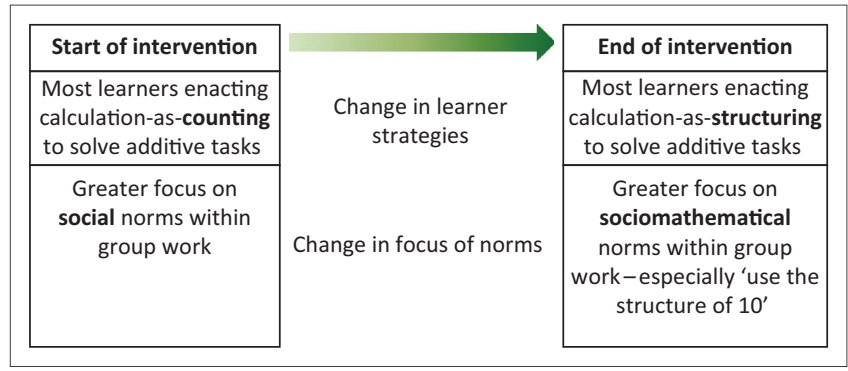

FIGURE 1: A pictorial view of changes in learner strategies and the type of norms in focus across intervention period.

Hence, more focus had to be placed on initiating and enacting SNs in both groups during earlier intervention lessons to get to a place of shared meaning making (Figure 1). More importantly, our data goes a step further to show that a greater proportion of all norms established over time in each group were SMNs (Figure 1). So, early number learning came more sharply into focus during the second half of intervention as groups got better at working collaboratively. Finally, what became very clear from our analysis of normative behaviour within groups is that the sociomathematical norm 'use the structure of $10^{\text {' became a }}$ focal point during intervention. We believe that putting participants' use of base-10 structure at the foreground of intervention is what leveraged their early number learning gains (Morrison 2018, 2020) and thus enabled their progression from less-efficient additive strategies based on counting to more sophisticated strategies premised on the base-10 structure. Whilst the relatively small sample size does not allow us to make broad claims about these findings, we believe that the outcomes point to the usefulness of closer attention to the affordances to learning early number skills that are linked to the establishment of social and SMNs in collaborative settings.

\section{Acknowledgements Competing interests}

The authors have declared that they have no financial or personal relationships that many have inappropriately influenced them in writing this article.

\section{Authors' contributions}

S.M. was the lead author of the article and the other authors read, commented and added to drafts of the article.

\section{Ethical considerations}

Ethical clearance was provided by the University of the Witwatersrand (clearance number: 2013ECE104D).

\section{Funding information}

The work reported in this article is located within the South African Numeracy Chair Wits Maths ConnectPrimary project at the University of the Witwatersrand. It is generously supported by the FirstRand Foundation 
(with the RMB), Anglo American Chairman's fund, the Department of Science and Technology and the National Research Foundation.

\section{Data availability}

Data sharing is not applicable to this article as no new data were created or analysed in this study.

\section{Disclaimer}

The views and opinions expressed in this article are those of the authors and do not necessarily reflect the official policy or position of any affiliated agency of the authors.

\section{References}

Anghileri, J., 2006, 'Scaffolding practices that enhance mathematics learning', Journal of Mathematics Teacher Education 9(1), 33-52. https://doi.org/10.1007/ s10857-006-9005-9

Askew, M., 2016, Transforming primary mathematics: Understanding classroom tasks, tools and talk, Updated and rev. edn., Routledge, London.

Boaler, J., 1998, 'Open and closed mathematics: Student experiences and understandings', Journal for Research in Mathematics Education 29(1), 41-62. https://doi.org/10.5951/jresematheduc.29.1.0041

Cobb, P., 1995, 'Mathematical learning and small-group interaction: Four case studies', in P. Cobb \& H. Bauersfeld (eds.), The emergence of mathematical meaning: Interaction in classroom cultures, pp. 25-129, Lawrence Erlbaum, Hillsdale, NJ.

Cobb, P. \& Yackel, E., 1996, 'Constructivist, emergent, and sociocultural perspectives in the context of developmental research', Educational Psychologist 31(3-4), 175-190. https://doi.org/10.1080/00461520.1996.9653265

Ellemor-Collins, D. \& Wright, R., 2009, 'Structuring numbers 1 to 20: Developing facile addition and subtraction', Mathematics Education Research Journal 21(2), 50-75. https://doi.org/10.1007/BF03217545

Ensor, P., Hoadley, U., Jacklin, H., Kuhne, C., Schmitt, E., Lombard, A. et al., 2009 'Specialising pedagogic text and time in foundation phase numeracy classrooms', Journal of Education 47(1), 5-30.

Erickson, F., 1982, 'Classroom discourse as improvisation: Relationships between academic task structure and social participation structure in lessons', in L.C. Wilkinson (ed.), Communicating in the classroom, pp. 153-182, Academic, New York.

Gardee, A., 2019a, 'Social relationships between teachers and learners, learners' mathematical identities and equity', African Journal of Research in Mathematics, Science and Technology Education 23(2), 233-243. https://doi.org/10.1080/1811 7295.2019.1662641

Gardee, A., 2019b, 'Relationship between teachers' practices and learners' mathematical identities', International Journal of Mathematical Education in Science and Technology 52(3), 1-27. https://doi.org/10.1080/0020739X.2019.1688403

Kilpatrick, J., Swafford, J. \& Findell, B., 2001, Adding it up: Helping children learn mathematics, National Academy Press, Washington, DC.

Maphala, M.C. \& Mpofu, N., 2018, 'Embedding values in the South African curriculum: By design or default?', South African Journal of Education 38(3), a1437. https:// doi.org/10.15700/saje.v38n3a1437
McClain, K. \& Cobb, P., 2001, 'An analysis of development of sociomathematical norms in one first-grade classroom', Journal for Research in Mathematics Education 32(3), 236-266. https://doi.org/10.2307/749827

McIntosh, A., Reys, R.E. \& Reys, B.J., 1997, 'Mental computation in the middle grades: The importance of thinking strategies', Mathematics Teaching in the Middle School 2(5), 322-327. https://doi.org/10.5951/MTMS.2.5.0322

Morrison, S.S., 2018, 'Using maths recovery principles in a South African primary school', Ph.D, University of the Witwatersrand, Johannesburg.

Morrison, S.S., 2020, 'Maths recovery can improve early number learning in the South African context', in M. Inprasitha, N. Changsri \& N. Boonsena (eds), Interim proceedings of the 44th conference of the International group for the psychology of mathematics education, vol. 1, pp. 394-402, PME, Khon Kaen.

NCTM, 2000, Principles and standards for school mathematics, NCTM, Reston, VA.

O'Connor, M.C. \& Michaels, S., 1996, 'Shifting participant frameworks: Orchestrating thinking practices in group discussion', Discourse, learning, and schooling 63, 103.

Roberts, N. \& Venkat, H., 2016, 'Learning from disruptive classroom behaviour in a grade 2 mathematics lesson', South African Journal of Childhood Education 6(1), 1-10. https://doi.org/10.4102/sajce.v6i1.377

Rodríguez-Planas, N. \& Nollenberger, N., 2018, 'Let the girls learn! It is not only about math ... it's about gender social norms', Economics of Education Review 62, 230-253. https://doi.org/10.1016/j.econedurev.2017.11.006

Schollar, E., 2008, Final report: The primary mathematics research project 2004-2007 - Towards evidence-based educational development in South Africa, Eric Schollar \& Associates, Johannesburg.

Segalo, L. \& Rambuda, A.M., 2018, 'South African public school teachers' views on right to discipline learners', South African Journal of Education 38(2), 1-7. https:// doi.org/10.15700/saje.v38n2a1448

Shumway, J.F., 2011, Number sense routines: Building numerical literacy every day in grades $\mathrm{K}-3$, Stenhouse Publishers, Portland.

Solomon, I. \& Fataar, A., 2011, 'A conceptual exploration of values education in the context of schooling in South Africa', South African Journal of Education 31(2), 224-232. https://doi.org/10.15700/saje.v31n2a482

Spaull, N., 2013, South Africa's education crisis: The quality of education in South Africa 1994-2011, Centre for Development and Enterprise, Johannesburg, pp. 1-65.

Spaull, N., Van der Berg, S., Wills, G., Gustafsson, M. \& Kotzé, J., 2016, Laying firm foundations: Getting reading right, Report to the PSPPD, University of Stellenbosch, Stellenbosch.

Steffe, L.P. \& Thompson, P.W., 2000, 'Teaching experiment methodology: Underlying principles and essential elements', in R. Lesh \& A.E. Kelly (eds.), Handbook of research design in mathematics and science education, pp. 267-306, Erlbaum, Hillside, NJ.

Widodo, S.A., Turmudi, T. \& Dahlan, J., 2019, 'Can sociomathematical norms be developed with learning media?', Journal of Physics Conference Series 1315 012005. https://doi.org/10.1088/1742-6596/1315/1/012005

Wright, R.J., Martland, J. \& Stafford, A.K., 2006, Early numeracy: Assessment for teaching and intervention, Sage, London.

Yackel, E. \& Cobb, P., 1996, 'Sociomathematical norms, argumentation, and autonomy in mathematics', Journal for Research in Mathematics Education 27(4), 458-477. https://doi.org/10.2307/749877

Yackel, E. \& Rasmussen, C., 2002, 'Beliefs and norms in the mathematics classroom', in G.C. Leder, E. Pehkonen \& G. Törner (eds.), Beliefs: A hidden variable in mathematics education?, pp. 313-330, Springer, Dordrecht.

Van den Heuvel-Panhuizen, M., 2008, Children learn mathematics: A learning teaching trajectory with intermediate attainment targets for calculation with whole numbers in primary school, Sense, Dordrecht.

Wright, R., Ellemor-Collins, D. \& Tabor, P., 2012, Developing number knowledge: Assessment, teaching and intervention with 7-11 year-olds, Sage, London.

Wright, R., Martland, J. \& Stafford, A., 2006, Early Numeracy: Assessment for teaching and intervention, 2 nd edn., Sage, London. 